\title{
Case of Resistant Epileptic Encephalopathy a Child with Microcephalic Capillary Malformation Syndrome
}

ISSN: 2576-9200

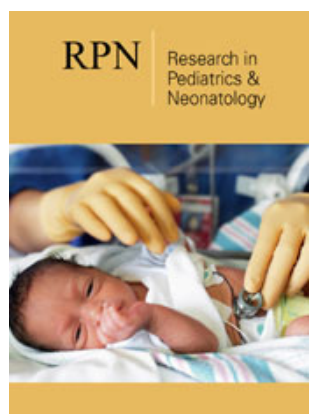

${ }^{* 1}$ Corresponding author: Schugareva LM, Children's Hospital, Russia

Submission: 非 April 01, 2019

Published: 㠿April 30, 2019

Volume 3 - Issue 3

How to cite this article: Schugareva L, Shumeeva A . Case of Resistant Epileptic Encephalopathy a Child with Microcephalic Capillary Malformation Syndrome. Res Pediatr Neonatol. 10(2). RPN.000564.2019.

DOI: 10.31031/RPN.2019.03.000564

Copyright@ Schugareva LM, This article is distributed under the terms of the Creative Commons Attribution 4.0 International License, which permits unrestricted use and redistribution provided that the original author and source are credited.

\author{
Schugareva $\mathrm{LM}^{1 *}$ and Shumeeva $\mathrm{AG}^{1}$ \\ ${ }^{1}$ Children's Hospital, Russia
}

\section{Introduction}

The most common causes of the drug-resistant epilepsy in children are genetic damages and congenital malformations of the brain. The microcephaly-capillary malformation syndrome (MICCAP) is an inherited disorder that is most frequently characterized by severe progressive microcephaly, early-onset refractory epilepsy, capillary malformations spread across the body. This paper describes a case of MICCAP in the infant presented with the early-onset drug-resistant epilepsy, microcephaly, spastic tetraplegia, profound developmental delay, multiple small capillary hemangiomas in the skin, hypoplasia of fingers. A novel homozygous mutation of STAMBP gene (c188A>G; chr2:74058171rs781694797) in exon 2 was revealed. The same mutation was found in both parents. The antiepileptic drug combination therapy was given.

Resistant in the treatment of epileptic encephalopathy in childhood in a significant amount due to a mutation of the nucleotide sequence of the genome, or congenital abnormalities of the brain. The literature described a rare microcephalic-capillary malformation syndrome (Microcephaly-capillary malformation, MIC-CAP), manifested from the first month of life by the early onset of treatment-resistant epilepsy, severe progressive microcephaly, spastic tetra paresis, global developmental delay, multiple, small-sized capillary malformations on the body and hypoplastic terminal phalanges Table 1.

A boy delivered from II Pregnancy 30-year-old healthy woman, who had viral infection, proteinuria, anemia in the 3rd trimester of pregnancy. Father is healthy. Tere was no any familial risk of epilepsy. The elder sister 6 years is healthy. Delivery was on $37 / 38$ weeks by emergency Cesarean section due to the acute hypoxia on the fetus. Weight $2280 \mathrm{~g}$, length $45 \mathrm{~cm}$. The Apgar score is $7 / 8$ points. The child was transferred to children's hospital on the $2^{\text {nd }}$ day of life due to depressed level of consciousness. The presence of cranio-fascial dysmorphy were assessed-head circumference $31.5 \mathrm{~cm}$ (less than 3 standard deviations), round face, wide and short nose, drooping corners of the mouth (Figure 1). Small capillary malformations spread diffusely on the body. There was also a shortening of the distal phalanges. He had male sexual organs.

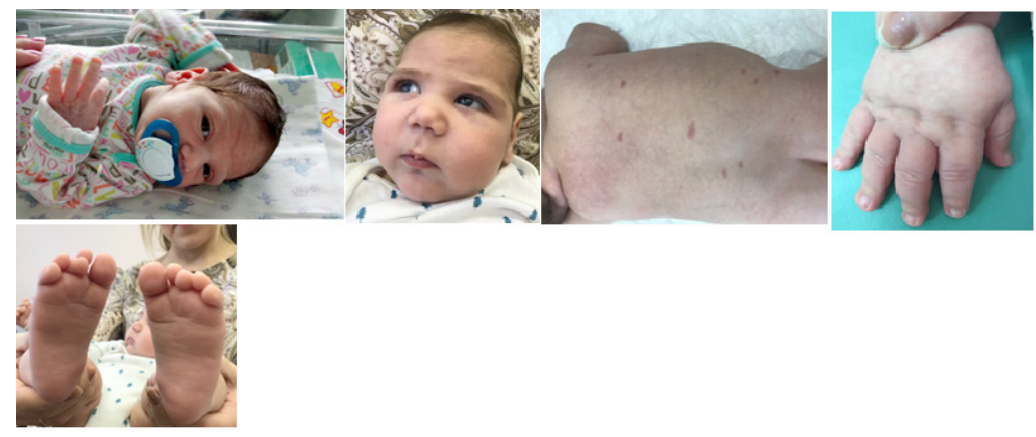

Figure 1: Boy M.R. A: 5-day; B: 5mth. Cranio-facial dysmorphy: microcephaly, round face, wide and short back of the nose, drooping corners of the mouth; C: Multiple rounded capillary hemangiomas; D, E: Shortening of the distal phalanges. 
On the $6^{\text {th }}$ day, the first generalized epileptic seizures developed without apnoe. From the age of 1-month myoclonic jerks and generalized tonic clonic seizures were continued. VideoEEG recording at the age of 1 month on EEG slow background activity with tiform activity "sharp slow wave" with periods of depression rhythm (Burst suppression patterns) (Figure 2). Taking into consideration the clinical picture of seizures and EEG data, the child was diagnosed «Infant epileptic encephalopathy Syndrome Ohtahara. On EEG at the age of 2 months the deterioration of the background rhythm, the increase in the index of epileptiform activity, hypsarrhythmia (Figure 3).

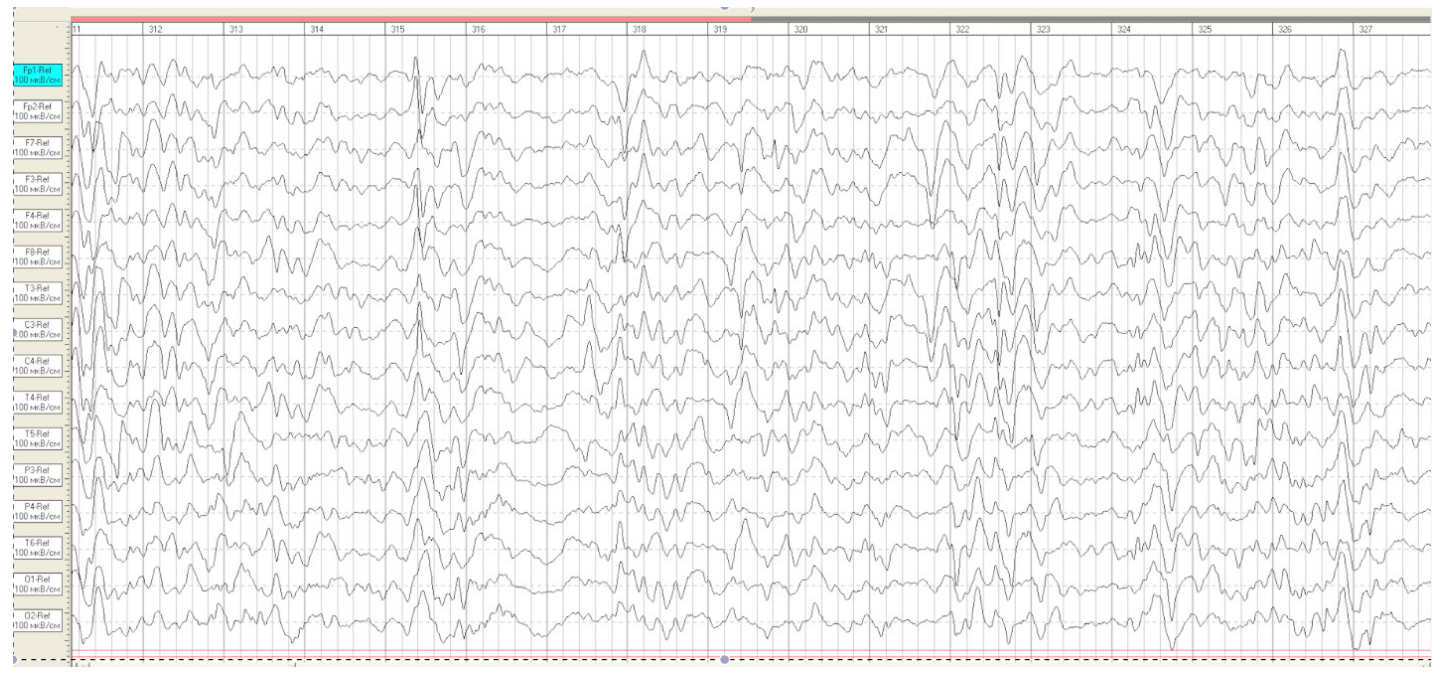

Figure 2: EEG M.R., 1 month. Burst suppression pattern.

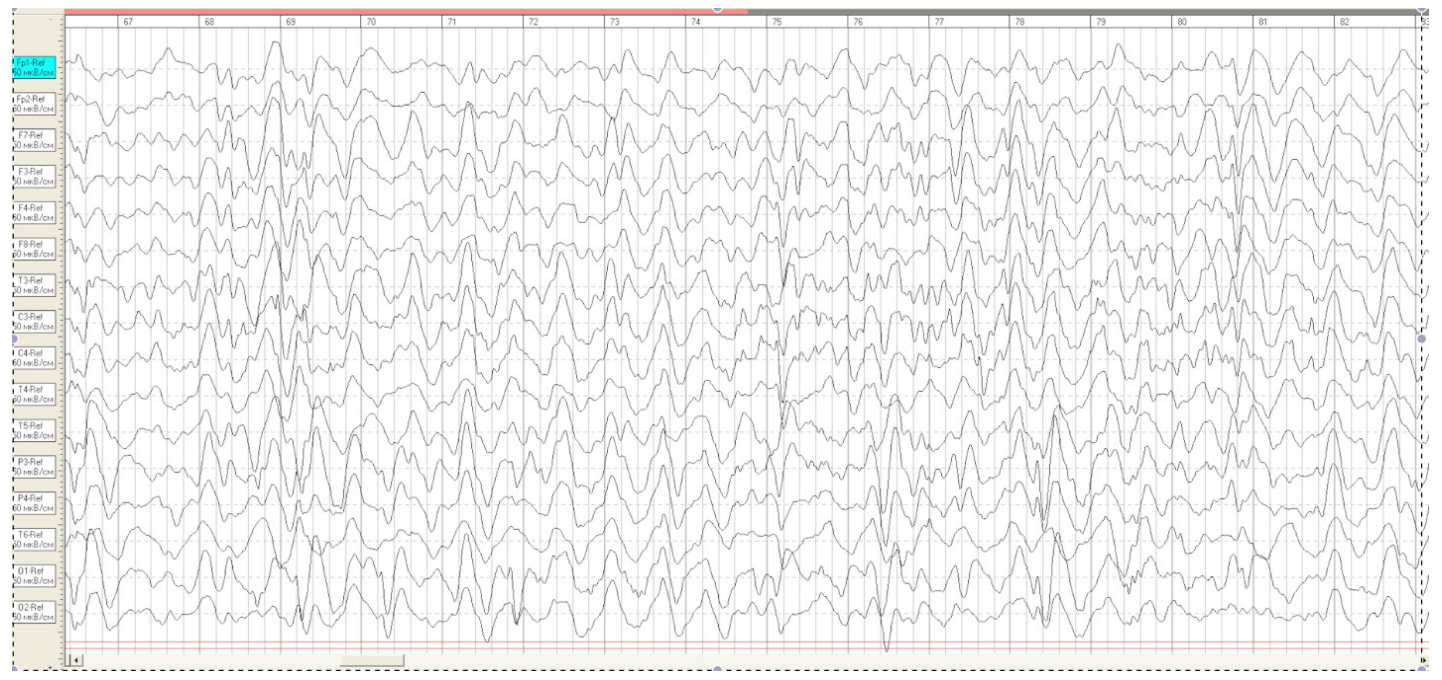

Figure 3: EEG M.R 2 month. Modified hypsarrhythmia..

His neurologic examination demonstrated diffuse hypotonia with hyporeflexia, divergent strabismus, facial masking. At the age of 21 days of life, MRI was studied and found to have abnormalities of the cerebral cortex characterized the simplified gyral pattern (Figure 4). When re-MRI was studied at the age of 2 months, microgyria in the sylvian region on both sides and diffuse atrophic changes in the cerebral hemispheres and cerebellum were assessed (Figure 4).

In the first of study we sought to evaluate the decreased myelination in the posterior limb of the internal capsule as the physiological (G). From the age of 2 months, decreased myelination assessed as pathological (Figure 5).
Bone age assessment of the wrist was performed at the age of 4 months, ossification centers in carpal bones were not not have been detected. At the age of 4 months, a genetic examination carried out, a previously undescribed variant of the nucleotide sequence was diagnosed in exon 2 of the STAMBP gene chr2: 74058171rs781694797 188A $>\mathrm{G}$ in the homozygous state, resulting in the replacement of the amino acid p.Tyr63Cys in 63 position of the protein. This type of mutation was also detected in the father and mother in the heterozygous state. This variant is considered as pathogenic, related to the patient's phenotype.

Even though existing antiepileptic drugs namely valproic acid, levetiracetam, lamotrigine, clonazepam, vigabatrin, seizures were 
continued and by 7 months were transformed into infantile spasms with registration of hypsarrhythmia on EEG (Figure 6). Thus, the child recorded the transformation of Otahara syndrome into West syndrome. From the age of 12 months, multifocal epileptic activity was registered on the EEG (Figure 7). By the age of 1.5 years, the boy develops with the global delay. Convulsive syndrome persists in the form of jerks involving the muscles of the face; spasms and focal sizures. Improvement of the condition was achieved with the appointment of levetiracetam, clonazepam, lamotrigine. The fundus of the eye revealed optic nerves atrophy.

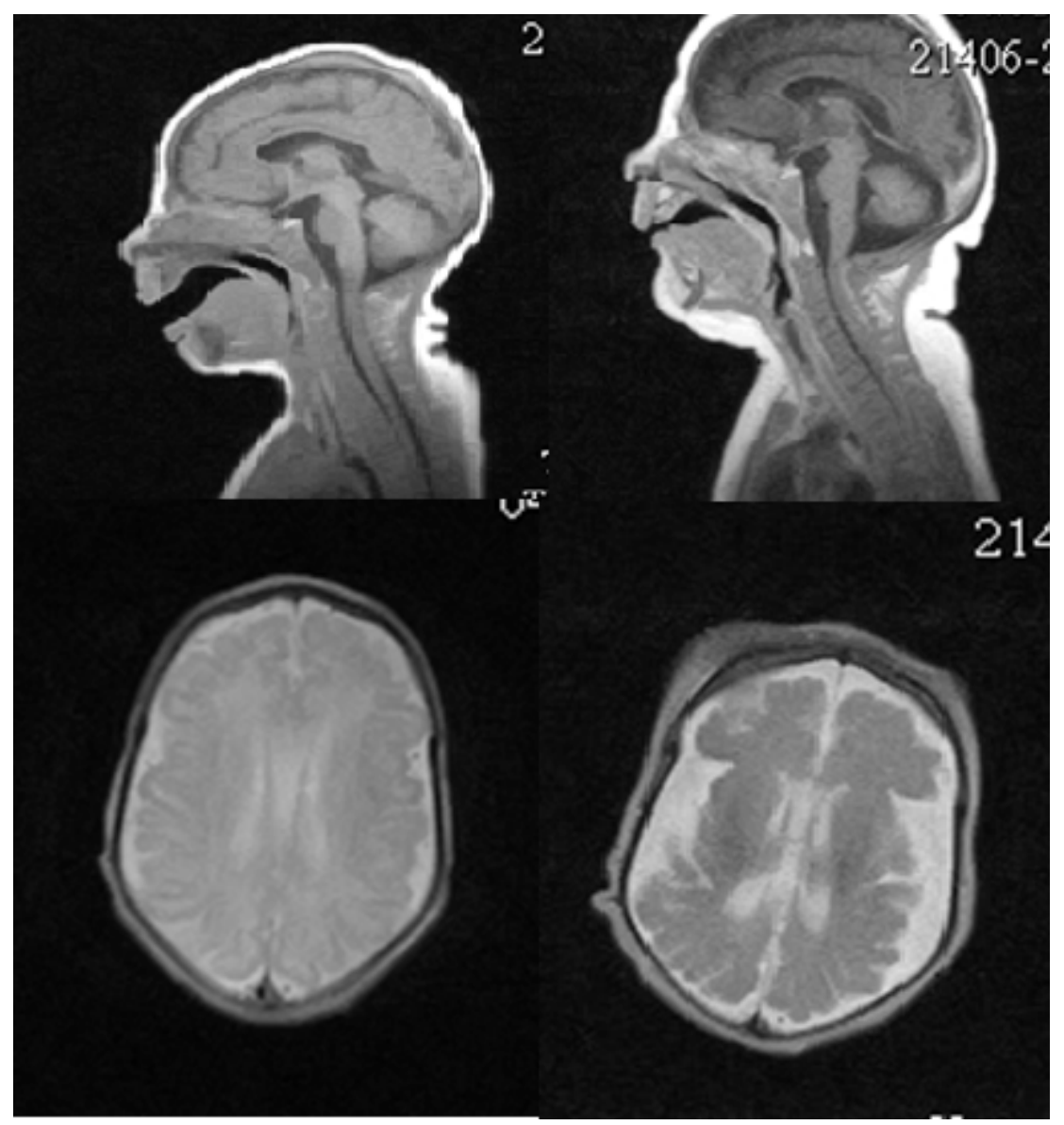

Figure 4: MRI of the brain M.R. at the 21 days of life $(A, C)$ and 2 months of life (B, D). A, C the pattern of "microcephaly with simplified gyral pattern". Polymicrogyria in the sylvian fissure region shown by the arrow (D).

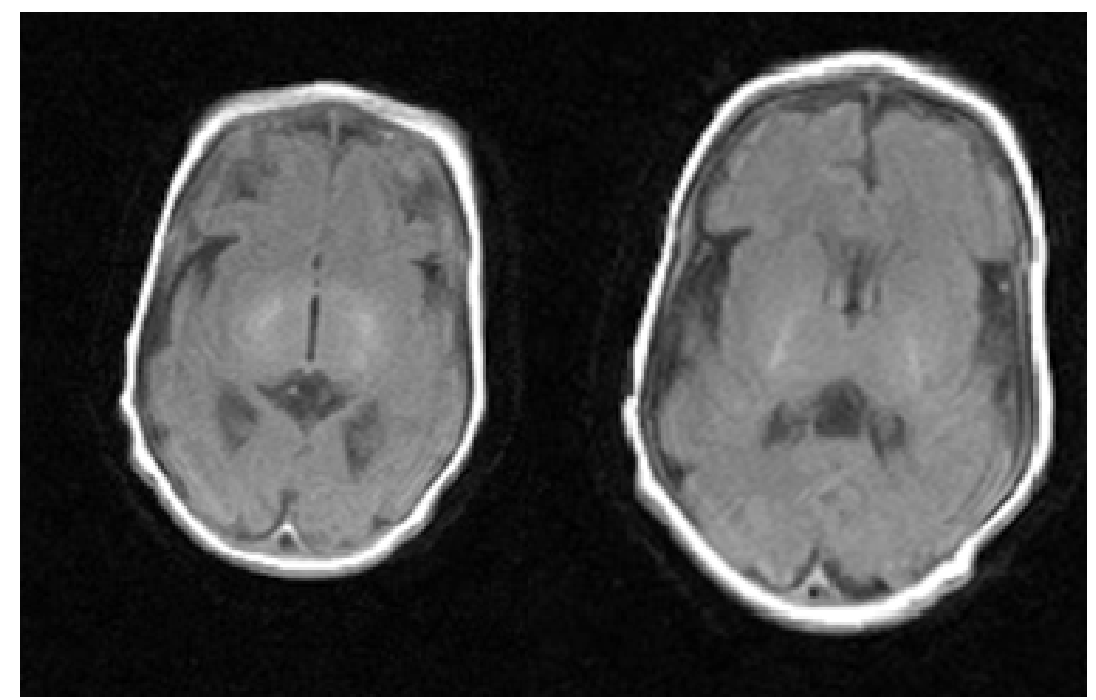

Figure 5: MRI of the brain of a boy M.R. at the age of 21 days (A) and 2 months (B). Signal changes in the PLIC are visually evaluated on FLAIR images is indicated by an arrow. 


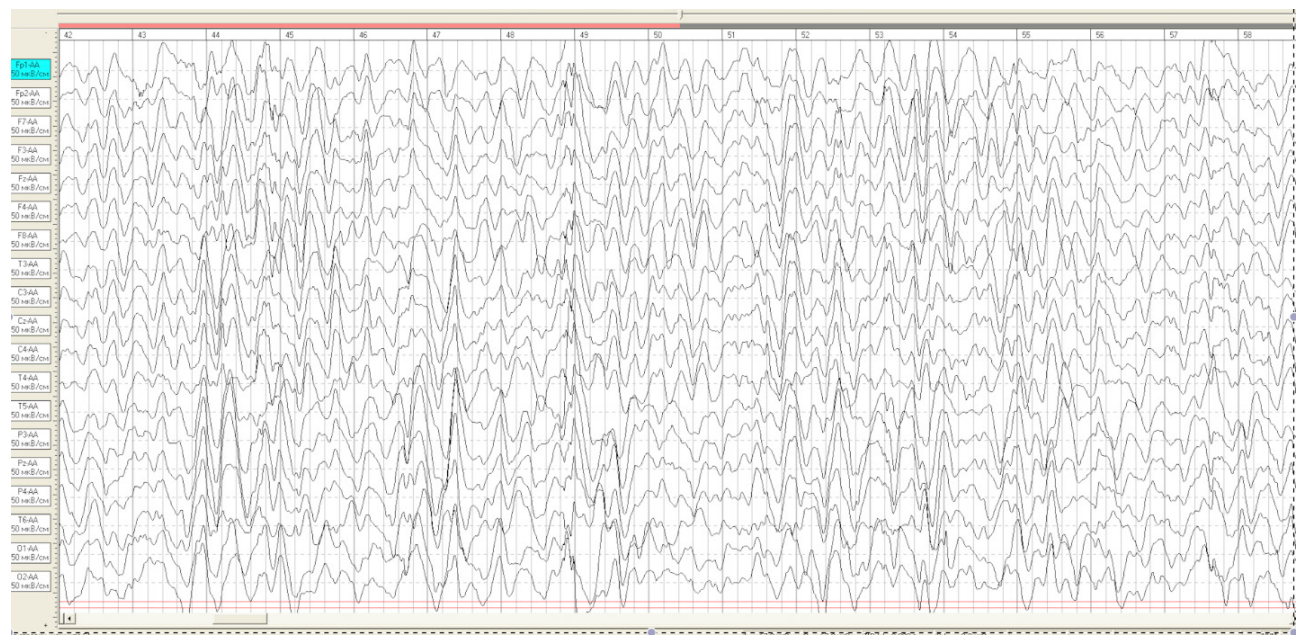

Figure 6: Boy, 7 months. EEG-the pattern of hypsarrhythmia.

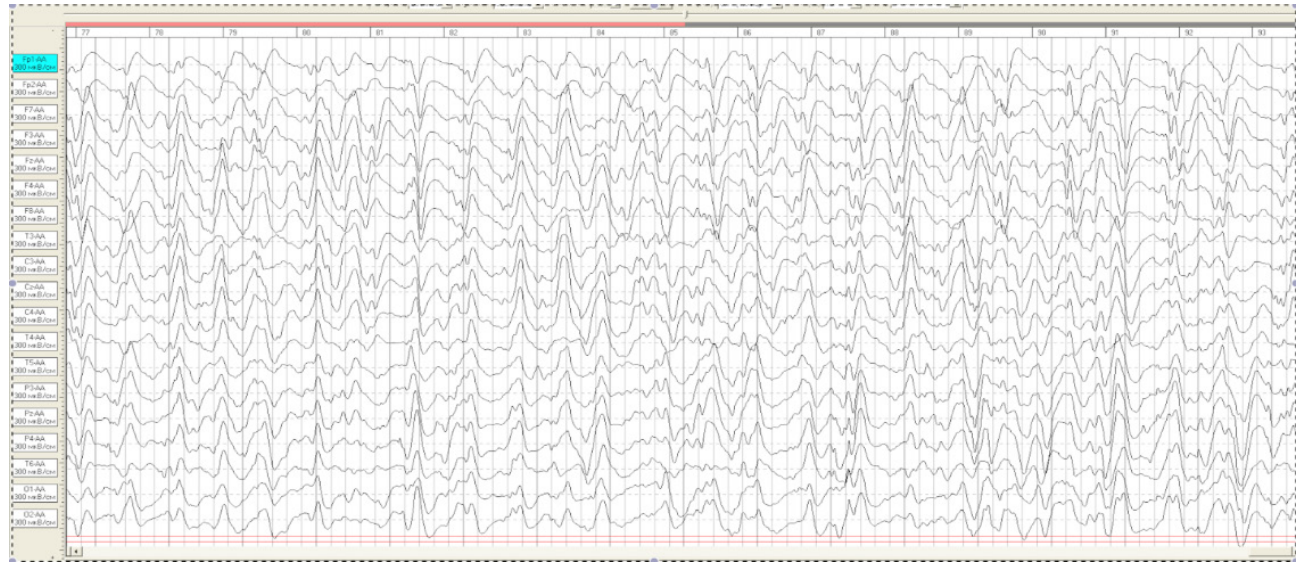

Figure 7: Boy M.R., 12 months. EEG multifocal epileptic activity.

Table 1: Signs and symptoms of microcephaly-capillary malformation syndrome according to the literature.

\begin{tabular}{|c|c|c|c|c|c|}
\hline \multirow{2}{*}{ Signs and Symptoms } & \multicolumn{5}{|c|}{ Affected Individuals } \\
\hline & $\mathrm{f}$ & $\mathrm{m}$ & $\mathrm{m}$ & $\mathrm{m}$ & $\mathrm{m}$ \\
\hline Small stature & - & - & - & + & + \\
\hline Head circumference at birth & $<6$ & $<4$ & $<2$ & $<2$ & $<4$ \\
\hline Cranio-facial dysmorphia & + & + & + & + & + \\
\hline Capillary angiomas & + & + & + & + & + \\
\hline Hypoplasia of the distal phalanges of the arms or legs & + & + & + & + & + \\
\hline Angioma of the cerebellum & - & - & - & + & - \\
\hline Heart defects & - & $=$ & - & + & + \\
\hline Anomaly of the urogenital tract & - & - & - & - & + \\
\hline Resistant neonatal epilepsy & + & + & + & + & + \\
\hline Infantile spasms & + & - & + & no data & no data \\
\hline myoclonus & + & - & + & + & - \\
\hline Spastic tetraparesis & + & + & + & + & + \\
\hline
\end{tabular}




\begin{tabular}{|c|c|c|c|c|}
\hline Profound developmental delay & + & + & + & + \\
\hline Small for gestational age & + & + & + & + \\
\hline Microcephaly with simplified gyral pattern & + & + & + & + \\
\hline Subarachnoid extension & + & + & + & + \\
\hline Reduced hippocampal volume & + & + & + & + no data \\
\hline Hypomyelination & + & + & + & - \\
\hline
\end{tabular}

\section{Discussion}

The first mutations due to MIC-CAP syndrome (MicrocephalyCutaneous Capillary Malformation Syndrome) were identified by exome sequencing. Some of the patients had previously been reported by Carter et al., Isidor et al. \& Mirzaa et al. [1-3]. The phenotype was characterized by severe progressive microcephaly, early-onset refractory epilepsy, profound developmental delay, and multiple small capillary malformations spread diffusely on the body. Additional features, such as dysmorphic facial features and distal limb abnormalities, were also described. MIC-CAP in the database OMIM: 614261. The literature describes the main and additional clinical signs of MIC-CAP: facial dysmorphia, hypoplastic terminal phalanges, congenital defects of the valves of the heart, hearing loss, vesicoureteral reflux, etc.

\section{Molecular genetics}

Cellular studies by McDonell et al. [4] showed that siRNAmediated silencing of STAMBP in human medulloblastoma cells caused increased amounts of conjugated-ubiquitin aggregates. Patient lymphocytes showed a similar aggregation. The abnormal cellular phenotype was associated with induction of apoptosis and increased autophagic flux. Protein studies showed decreased or absent STAMBP protein in mutant cells. In 10 patients from 9 families with microcephaly-capillary malformation syndrome (MICCAP; 614261), McDonell et al. [4] identified biallelic mutations in the STAMBP gene. A boy was born from pregnancy II, a phenotypically healthy woman. Baby was born on 37/38 week with signs of intrauterine hypotrophy (MT $=2280 \mathrm{~g}$, length $=45 \mathrm{~cm}$ ). From birth, a child had congenital microcephaly (less than 3 centiles), cranio-facial dysmorphism, multiple capillary hemangiomas on the body, hypoplasia of the distal fingers. Somatic status without features.

Since the neonatal period, epilepsy resistant to therapy developed. By the age of 7 months-complex partial and jerk events transformed into infant spasms. pattern of hypsarrhythmia was registered on the EEG. From the age of 12 months, according to the criteria of ILAE, a pattern of multifocal epileptic activity was registered, "resistant to treatment of epilepsy" was confirmed. At the age of 7 months-West syndrome was registered and to 1 year of life Markland-Blume-Otahara syndrome (multifocal epilepsy) was proposed. Just now the boy is 1,5 years old. Profound developmental delay was developed- significantly delayed in the cognitive and physical development: delayed in motor skills, speech, cognitive skills, and social and emotional development. On examination, the myoclonus appears at rest, on keeping in day time and to look for the stimulus sensitivity and related to focal myoclonus that occurs in symptomatic epilepsy, in the setting of infection, inflammation, vascular disease, trauma or tumors. Epileptic spasms persist up to 5 times a day.

According to the results of Sanger Sequencing, the mutation in 2 exon of the STAMBP gene chr2: 74058171rs781694797 $188 \mathrm{~A}>\mathrm{G}$ in the homozygous state was also detected in the father and mother (in the heterozygous state). The STAMBP gene encodes a deubiquitinating isopeptidase that has a key role in cell surface receptor-mediated endocytosis and sorting. So, clinical examination, radiographs and sequencing described in the case with serious clinical manifestations similar to MIC-CAP.

\section{Conclusion}

The detected malformation of the brain (microcephaly) in the represented case wasn't the only reason of the drug-resistant epilepsy. That is why it's important to search for the pathogenetic mutations as the probable reason of the developing resistant epilepsy in infants. According to the reports described in a literature the clinical polymorphism of MICCAP took place in this case. The novel mutation of STAMBP gene with the typical clinical characteristics was found. It highlights the significance of genetic testing in refractory epilepsy and contributes to the updating of a genetic database. To the best of our knowledge, this is the first report of such condition described in Russia. Relying on existing evidences of reducing abnormal neuronal activity up to $3^{\text {rd }}$ year of age it is rational to keep treating with the anti-epileptic drug combination therapy and refrain from surgery [5-12].

\section{References}

1. Carter M, Geraghty M, Cruz L, De la, Reichard R, et al. (2011) A new syndrome with multiple capillary malformations, intractable seizures, and brain and limb anomalies. American Journal of Medical Genetics Part A 155(2): 301-306.

2. Isidor B, Barbarot S, Bénéteau C, Caignec C, David A (2011) Multiple capillary skin malformations, epilepsy, microcephaly, mental retardation, hypoplasia of the distal phalanges: Report of a new case and further delineation of a new syndrome. American Journal of Medical Genetics Part A 155(6): 1458-1460.

3. Mirzaa G, Paciorkowski A, Christopher, Marcia C (2011) The microcephaly-capillary malformation syndrome. American Journal of Medical Genetics Part A 155(9): 2080-2087.

4. Laura M, McDonell, Mirzaa G, Alcantara D, Boycott KM, et al. (2013) Mutations in STAMBP, encoding a deubiquitinatin genzyme, cause microcephaly-capillary malformation syndrome. Nature Genetics 45(5): 556-562. 
5. Adachi Y, Poduri A, Kawaguch A, Yoon G, Salih MA, et al. (2011) Congenital microcephaly with a simplified gyral pattern: associated findings and their significance. American Journal of Neuroradiology 32(6): 11231129.

6. Kuzniecky R (2015) Epilepsy and malformations of cortical development: new developments. Current Opinion in Neurology 28(2): 151-157.

7. Desikan RS, Barkovich AJ (2016) Malformations of cortical development. Ann Neurol 80(6): 797-810.

8. Demikova NS, Victoria S, Nataliya L, Nataliya L, Nina A, et al. (2018) First report of microcephaly-capillary malformations syndrome in Russia. Egyptian Journal of Medical Human Genetics 19 (2): 147-150.

9. Pavlović M, Neubauer D, Tawari A, Heberle LC (2014) The microcephaly-capillary malformation syndrome in two brothers with novel clinical features. Pediatric Neurology 51(4): 560-565.
10. Hori I, Miya F, Negishi Y, Hattori A, Ando N, et al. (2018) A novel homozygous missense mutation in the SH3-binding motif of STAMBP causing microcephaly-capillary malformation syndrome. Journal of Human Genetics 63(9): 957-963.

11. Blokhin D, Chmutin EF, Ivanov PK (2011) Molecular targets for antitumor therapy: signal transduction pathways and epigenetic modulators. Russian Biotherapeutic Journal 4(10): 81-88.

12. Kwan P, Arzimanoglou A, Berg A, Brodie MJ, Allen H, et al. (2009) Definition of drug resistant epilepsy: consensus proposal by the ad hoc task force of the ILAE C commission on therapeutic strategies. Epilepsia 51(6): 1069-1077.

For possible submissions Click below: 